\title{
РЕНТГЕНОСТРУКТУРНЫЙ АНАЛИЗ СУЛЬФАТНЫХ ЦЕЛЛЮЛОЗ РАЗЛИЧНЫХ ПРОИЗВОДИТЕЛЕЙ
}

\author{
() М.О. Шевчук", М.А. Зильберглейт, Е.П. Шишаков \\ Белорусский государственный технологический университет, \\ ул. Свердлова, 13а, Минск, 220006 (Республика Беларусь), \\ e-mail:ddtpisticid@mail.ru
}

Предмет исследования - результаты рентгеноструктурного анализа сульфатных целлюлоз. Цель работы - сравнительный рентгеноструктурный анализ сульфатных целлюлоз различных производителей. Установлено, что показатели кристалличности и теплофизические свойства целлюлоз не влияют на прочность вискозного волокна.

Ключевые слова: целлюлоза сульфатная, рентгеноструктурный анализ, индекс кристалличности, степень кристалличности, коэффициент объемного теплового расширения, плотность, удельная теплоемкость.

\section{Введение}

Целлюлоза - самый распространенный природный полимер, абсолютная масса которого на нашей планете значительно превышает количество любого другого органического вещества. Она является важным сырьем для химической переработки, на основе которого можно получать различные технически ценные и во многих случаях незаменимые продукты и материалы [1, с. 5].

Настоящая работа выполнена по заказу ОАО «СветлогорскХимволокно» (Республика Беларусь). Заказ связан с трудностями переработки облагороженной целлюлозы в вискозное волокно. По мнению специалистов-производственников, эти затруднения вызваны широким распределением целлюлоз по молекулярным массам либо со значительными затруднениями при ксантогенировании, что в свою очередь связано с низкой доступностью кристаллической части целлюлозы для проникновения сероуглерода.

Рентгеноструктурный анализ (РСА) находит широкое применение в исследованиях кристаллической структуры целлюлозы. Он позволяет устанавливать параметры кристаллической решетки, определять тип и содержание кристаллической модификации, степень кристалличности, размер и дефектность кристаллов и ряд других характеристик, связанных со структурой полимера.

Степень кристалличности целлюлозы является важной структурной характеристикой целлюлозы, оказывающей влияние на физико-химические, теплофизические свойства и ее реакционную способность.

\section{Экспериментальная часть}

Для анализа использовался рентгеновский дифрактометр D8 Advance производства фирмы Bruker

Шевчук Михаил Олегович - ассистент кафедры органической химии, кандидат технических наук, тел.: (017) 327-63-54, e-mail: ddtpisticid@ mail.ru Зильберглейт Марк Аронович - доктор химических наук, тел.: (017) 327-72-30, e-mail: mazi@ list.ru Шишаков Евгений Павлович - ведущий научный сотрудник кафедры химической переработки древесины, кандидат технических наук, тел.: (017) 327-63-54, e-mail: ddtpisticid@mail.ru
AXS (Германия), использовано излучение К- $\alpha$ меди, выделенное никелевым фильтром, с длиной волны $\lambda=1,54 \AA$. Измерения проводились в пошаговом режиме в интервале углов 4-30 градусов с шагом 0,1 градуса, время счета одной точки 4 с. Полученные экспериментальные данные сглаживались при помощи пакета Microsoft Excel (вкладка «сглаживание линий на графике»).

\footnotetext{
* Автор, с которым следует вести переписку.
} 
В качестве параметра, подлежащего оценке, была рассчитана степень кристалличности образцов целлюлоз по методике Иоеловича [1, с. 49], методу Сегала [1, с. 49]. Первый метод состоял в определении отношения площадей под кристаллическими пиками к общей площади под кривой рассеяния. Расчет индекса кристалличности $\mathrm{C}_{\mathrm{\kappa}}$ по Сегалу основан на определении отношения интенсивности рефлекса 002 ( $\left.\mathrm{I}_{002}\right)$ за вычетом интенсивности рассеяния при угле $2 \Theta=19$ град $\left(\mathrm{I}_{\mathrm{a}}\right)$ к суммарной интенсивности рефлекса $\mathrm{I}_{002}[1, \mathrm{c} .44-55]$ :

$$
\mathrm{C}_{\mathrm{K}}=\left(\mathrm{I}_{002}-\mathrm{I}_{\mathrm{a}}\right) / \mathrm{I}_{002},
$$

где $\mathrm{I}_{\mathrm{a}}$ - интенсивность рассеяния при углах 17-19; $\mathrm{I}_{002}$ - интенсивность рефлекса 002.

Расчет величин размеров кристаллитов определяли по формуле Шеррера и по соотношению, взятому из работы Иоеловича [1, с. 44-55].

\section{Обсуждение результатов}

На рисунке представлены рентгенограммы бразильской $(a)$ и байкальской (б) целлюлоз производителей Бразилии (фирма Ваја) и России (Байкальский ЦБК) соответственно.

a)

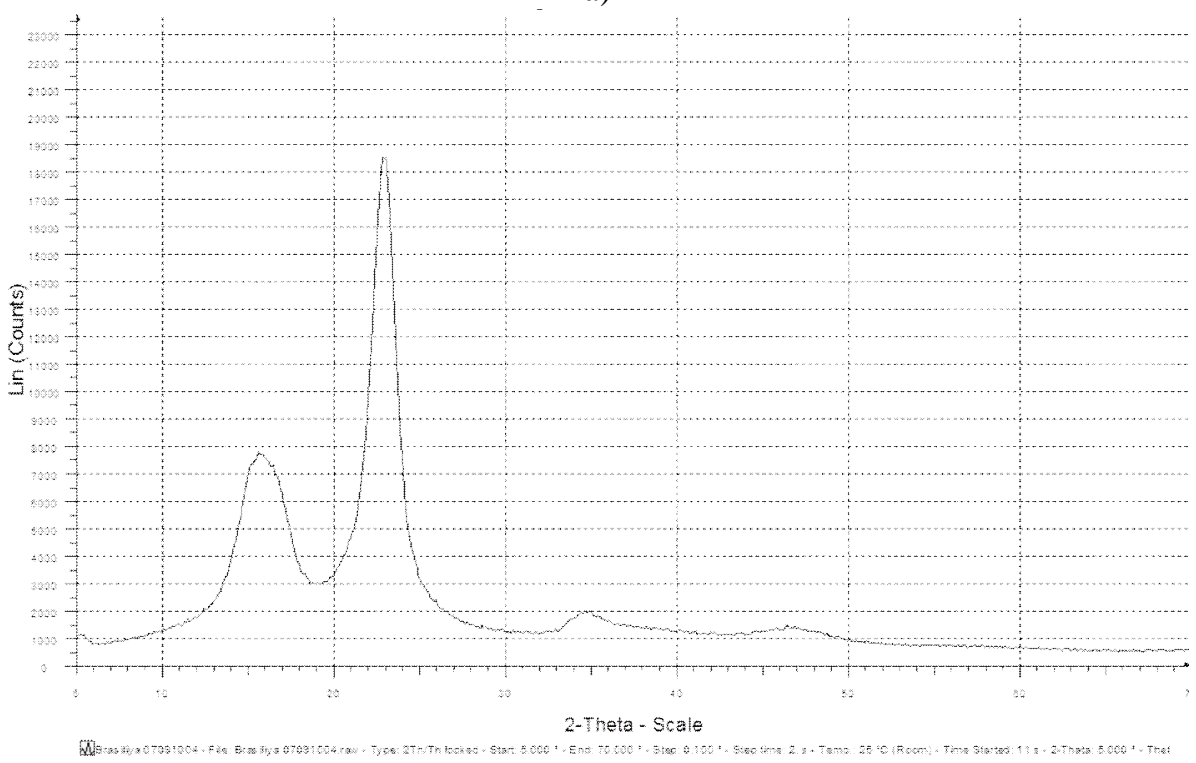

б)

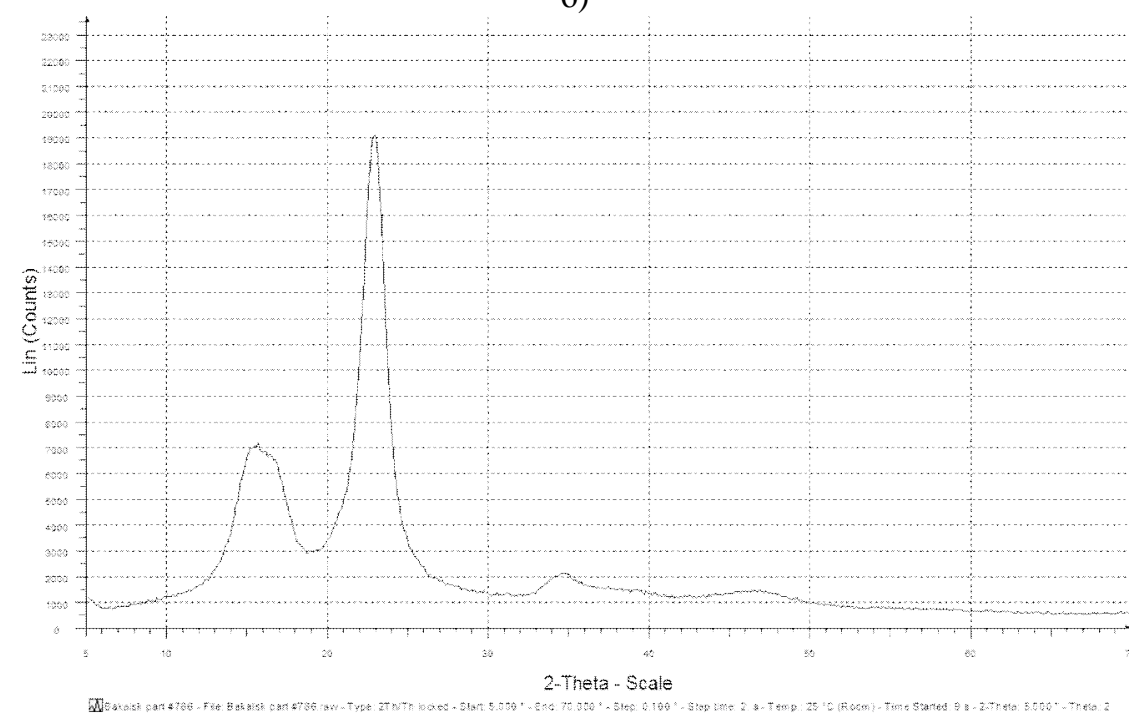

Рентгенограмма целлюлозы: $a$ - образец бразильской целлюлозы «Бразилия 07091004»; $\sigma$ - образец байкальской целлюлозы «Байкальск №786» 
В таблицах 1 и 2 приведены результаты обсчета полученных рентгенограмм бразильских и байкальских целлюлоз соответственно - определены среднее значение, среднеквадратическое отклонение, параметр Тагути, коэффициент вариации, размер кристаллита по Шерреру.

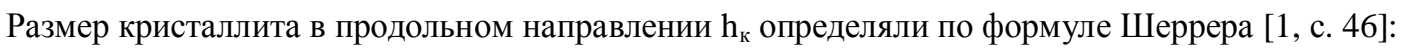

$$
h_{k}=k \frac{\lambda}{\Delta \varphi_{h_{k}} \cdot \cos \frac{\varphi_{m}}{2}},
$$

где $\mathrm{k}$ - коэффициент, зависящий от формы кристалла (для кристаллов кубической формы k $\approx 0,9$ ); $\lambda-$ длина волны; $\varphi_{m} / 2$ - полуширина рефлекса, обусловленная размерами кристаллита; $\Delta \varphi_{h_{k}}-$ брегговский угол.

Границы применимости данного метода по определению размеров кристаллитов - от 10 до $1000 \AA$, ошибка измерения - не более 10-20 А.

Таблица 1. Характеристики надмолекулярной структуры целлюлозы фирмы Ваја (Бразилия)

\begin{tabular}{l|c|c|c}
\hline Наименование образца, показатель & $\begin{array}{c}\text { Степень } \\
\text { кристалличности, \% }\end{array}$ & $\begin{array}{c}\text { Индекс } \\
\text { кристалличности }\end{array}$ & $\begin{array}{c}\text { Размер кристаллита } \\
\text { по Шерреру, А }\end{array}$ \\
\hline Бразилия 07090702 & 74,8 & 0,59 & 44,0 \\
Бразилия 07091002 & 75,7 & 0,59 & 45,0 \\
Бразилия 07091004 & 68,4 & 0,60 & 55,5 \\
$\quad$ №07090812 & 69,5 & 0,64 & 55,5 \\
Бразилия 0012401 & 68.8 & 0.66 & 46,5 \\
Бразилия 0012311018 & 74,4 & 0,6 & 48,8 \\
\hline Среднее значение & 73,2 & 0,59 & 5,24 \\
Среднеквадратическое отклонение & 3,38 & 0,0390 & 9,31 \\
Параметр Тагути & 21,64 & 15,13 & 10,74 \\
Коэффициент вариации & 4,62 & 6,61 & \\
\hline
\end{tabular}

Таблица 2. Характеристики надмолекулярной структуры целлюлозы Байкальского ЦБК

\begin{tabular}{|c|c|c|c|}
\hline Наименование образца & $\begin{array}{c}\text { Степень } \\
\text { кристалличности, \% }\end{array}$ & $\begin{array}{c}\text { Индекс } \\
\text { кристалличности }\end{array}$ & $\begin{array}{c}\text { Размер кристаллита по } \\
\text { Шерреру, }\end{array}$ \\
\hline Байкальск №1862 & 69,0 & 0,64 & 53,6 \\
\hline Байкальск №792 & 70,5 & 0,68 & 55,0 \\
\hline Байкальск №794 & 68,6 & 0,68 & 55,0 \\
\hline Байкальск №790 & 69,4 & 0,66 & 55,5 \\
\hline Байкальск №786 & 68,8 & 0,65 & 55,5 \\
\hline Байкальск №784 & 70,3 & 0,66 & 64,4 \\
\hline Байкальск 902 & 71.1 & 0,63 & 53,6 \\
\hline Среднее значение & 69,7 & 0,66 & 56,1 \\
\hline Среднеквадратическое отклонение & 0,96 & 0,0189 & 3,76 \\
\hline Параметр Тагути & 72,41 & 34,77 & 14,91 \\
\hline Коэффициент вариации & 1,38 & 2,88 & 6,70 \\
\hline
\end{tabular}

Определение величин плотности, удельного объема, коэффициент объемного теплового расширения, удельной теплоемкости, стандартной энтальпии взаимодействия с водой, количество воды, сорбированное целлюлозой при $\varphi=0,7$, определяли по формулам, приведенным в публикации Иоеловича [3].

Взаимосвязь между плотностью и степенью кристалличности [3]:

$$
d=\frac{1,44 \cdot 10^{3}}{(1-0,11 X)},
$$

где $X$ - степень кристалличности. 
Взаимосвязь между удельным объемом $V$ и степенью кристалличности [3]:

$$
V=\frac{(1-0,11 X) \cdot 10^{-3}}{1,44} .
$$

Коэффициент объемного теплового расширения аморфно-кристаллического полимера определяли по формуле [4]:

$$
a=1,5 \cdot 10^{-4}-\frac{1 \cdot 10^{-4} X}{X+1,125(1-X)} .
$$

Удельная теплоемкость целлюлозы при $300 K$ связана со степенью кристалличности уравнением

$$
C_{p}=1,270-0,074 X
$$

Между стандартной энтальпией взаимодействия целлюлозы с водой и содержанием аморфных областей (1-X) имеется следующая зависимость [5]:

$$
\Delta H^{0}=\Delta H_{\alpha}^{0}(1-X)
$$

Скорректированное значение энтальпии взаимодействия с водой аморфных областей целлюлозы $\Delta H_{a}^{0}=-170$ Дж/кг.

Количество воды $a$, сорбированное целлюлозой из паровой фазы при $\varphi=0,7$ определяли по формуле

\begin{tabular}{|c|c|c|}
\hline \multirow{2}{*}{ Свойство } & \multicolumn{2}{|c|}{ Значение показателя } \\
\hline & бразильская целлюлоза & байкальская целлюлоза \\
\hline Плотность, кг $/ \mathrm{M}^{3}$ & 1566 & 1560 \\
\hline Удельный объем, м³/кг & 0,639 & 0,641 \\
\hline Коэффициент объемного теплового расширения, $\mathrm{K}^{-1}$ & $79 \cdot 10^{-6}$ & $83 \cdot 10^{-6}$ \\
\hline Удельная теплоемкость, кДж/(кг·К) & 1,216 & 1,218 \\
\hline Стандартная энтальпия взаимодействия с водой, кДж/кг & $-45,6$ & $-51,5$ \\
\hline Количество воды, сорбированное целлюлозой при $\varphi=0,7$ & 0,068 & 0,077 \\
\hline
\end{tabular}

$$
a=0,255(1-X)
$$

Таблица 3. Результаты расчета некоторых свойств целлюлоз

Как видно и таблицы 3, характеристики исследованных образцов целлюлоз, рассчитанные по уравнениям 1-8, близки.

Виду того, что на практике бразильские целлюлозы перерабатываются легче и дают волокно с более высокими прочностными свойствами, нами была предпринята попытка связать результаты промышленного производства с данными, полученными при анализе рентгенограмм. Поскольку при оценке качества авторы придерживаются положений профессора Тагути, то нами были определены величины дисперсии, коэффициентов вариации и параметра Тагути (отношение среднего значения к среднеквадратичному отклонению) для 12 образцов целлюлоз. Оказалось, что по этим признакам наиболее стабильные показатели характерны для байкальской целлюлозы.

\section{Заключение}

При сравнительном изучении ряда целлюлоз, предназначенных для химической переработки, были найдены некоторые различия в физических свойствах байкальской и бразильской целлюлоз. В частности, значения коэффициента объемного теплового расширения, $\mathrm{K}^{-1}$, удельной теплоемкости, кДж/(кг·К), стандартной энтальпии взаимодействия с водой, кДж/кг, количество воды, сорбированное целлюлозой при $\varphi=0,7$ больше у байкальской целлюлозы. 
Среднее значение индекса кристалличности для бразильской целлюлозы выше, чем у байкальской, напротив, значение степени кристалличности выше у байкальской целлюлозы.

Коэффициенты вариации, которые, по мнению Тагути, определяют качество процесса, для индекса кристалличности, степени кристалличности и размера кристаллита по Шерреру выше у бразильской целлюлозы.

Таким образом, авторы не могут признать, что структурная организация целлюлозы, охарактеризованная при помощи таких показателей, как среднее значение индекса кристалличности, степень кристалличности, размер кристаллита по Шерреру являются определяющими в характеристике реакционной способности целлюлозы в процессе вискозообразования.

\section{Список литературь}

1. Методы исследования целлюлозы / под ред. В.П. Карливана. Рига, 1981. 264 с.

2. Гетце К. Производство вискозного волокна. М., 1958. 249 с.

3. Иоелович М.Я., Веверис Г.П. Определение степени кристалличности целлюлозы рентгенографическими методами // Химия древесины. 1987. №5. С. 72-80.

4. Кайминь И.Ф., Карливан В.П., Иоелович М.Я. Температурные переходы целлюлозы и их изменение в присутствии низкомолекулярных веществ // Известия АН ЛатвССР. 1979. №8. С. 112-123.

5. Цветков В.Г., Иоелович М.Я., Кайминь И.Ф., Рейзиньш Р.Э. Энтальпия взаимодействия целлюлозы различной степени кристалличности с водой // Химия древесины. 1980. №5. С. 12-15.

Поступило в редакичю 30 июня 2012 г.

После переработки 16 января 2013 г.

Shevchuk M.O.", Zil'bergleit M.A., Shishakov E.P. THE X-RAY ANALYSIS OF SULFATE CELLULOSE FROM DIFFERENT MANUFACTURERS

Belarusian State Technological University, ul. Sverdlova, 13a, Minsk, 220006 (Republic of Belarus),

e-mail:ddtpisticid@mail.ru

In article the questions connected with studying over-molecular of structure of sulphatic cellulose, intended for chemical processing are considered. As objects research the improved cellulose Baikal CPC (Russian Federation) and Baha firms (Brazil) served. Roentgenogram cellulose received on diffractometr D8 Advance firm Bruker AXS manufactures at radiation use K- $\alpha$ the copper, allocated with the nickel filter, from a long wave $\lambda=1,54 \AA$. Measurement was spent in a step-by-step mode in the range of corners of 4-30 degrees with step of 0,1 degrees, time of the account of one point 4 with. Have been defined degree crystalical, an index crystallical, the size crystalit, the density, specific volume, factor of volume thermal expansion, a specific thermal capacity, standard enthalpy interactions with water are calculated. It is established, that indicators crystalical and heatphysical properties of cellulose do not influence durability of a viscose fibre.

Keywords: sulphate cellulose, x-ray analysis, index of crystallinity, degree of crystallinity, the coefficient of volume thermal expansion, density, specific heat capacity

\section{References}

1. Metody issledovaniia tselliulozy. Ed. V.P. Karlivan. [Research methods cellulose. Ed. V.P. Karlivan]. Riga, 1981, 264 p. (in Russ.).

2. Gettse K. Proizvodstvo viskoznogo volokna. [Production of viscose fiber]. Moscow, 1958, 249 p. (in Russ.).

3. Ioelovich M.Ia., Veveris G.P. Khimiia drevesiny, 1987, no. 5, pp. 72-80. (in Russ.).

4. Kaimin' I.F., Karlivan V.P., Ioelovich M.Ia. Izvestiia AN LatvSSR, 1979, no. 8, pp. 112-123. (in Russ.).

5. Tsvetkov V.G., Ioelovich M.Ia., Kaimin' I.F., Reizin'sh R.E. Khimiia drevesiny, 1980, no. 5, pp. 12-15. (in Russ.).

Received June 30, 2012

Revised January 16, 2013

\footnotetext{
* Corresponding author.
} 
